\title{
Pengaruh Budaya Organisasi, Independensi, Objektivitas, Akuntabilitas, Dan Pengalaman Kerja Pada Kinerja Pengawas LPD
}

\author{
Kadek Pipit Winarsih ${ }^{1}$ \\ Ketut Alit Suardana ${ }^{2}$
}

\author{
${ }^{1}$ Fakultas Ekonomi dan Bisnis Universitas Udayana (Unud), Bali, Indonesia \\ email: ozy_kadek@yahoo.com / Telp: +62 81236106096 \\ ${ }^{2}$ Fakultas Ekonomi dan Bisnis Universitas Udayana (Unud), Bali, Indonesia
}

\begin{abstract}
ABSTRAK
Penelitian ini bertujuan untuk mengetahui pengaruh budaya organisasi, indpendensi, objektivitas, akuntabilitas, dan pengalaman kerja pada kinerja pengawas LPD di Kecamatan Tampaksiring Kabupaten Gianyar. Populasi dalam penelitian ini adalah keseluruhan LPD di Kecamatan Tampaksiring Kabupaten Gianyar yang masih aktif beroperasi. Teknik penentuan sampel menggunakan purposive sampling. Kriteria sampel yang digunakan adalah pengawas LPD di Kecamatan Tampaksiring yang telah menduduki jabatan minimal dua tahun. Jumlah sampel dalam penelitian ini adalah sebanyak 96 orang dari 32 LPD. Penelitian ini menunjukkan hasil bahwa indpendensi dan objektivitas secara parsial berpengruh positif namun tidak signifikan pada kinerja pengawas LPD. Akuntabilitas dan pengalaman kerja berpengruh positif dan signifikan pada kinerja pengawas LPD. Sedangkan budaya organisasi budaya organisasi berpengaruh negatif dan tidak signifikan pada kinerja pengawas LPD.

Kata Kunci: pengawas, kinerja, budaya organisasi, independensi, objektivitas, akuntabilitas, dan pengalaman kerja
\end{abstract}

\begin{abstract}
The purpose of this research was to determine the effect of organizational culture, independence, objectivity, accountability, and work experiencein supervisory performance $L P D$ in the Tampaksiring district Gianyar regency. The population of the research is the LPD that is still operating in the whole of Tampaksiring distric Gianyar regency. The sampling technique that used in this research is purposive sampling. Sample criteria used are LPD supervisors in Tampaksiring Distric who have occupied positions at least two years. The sample used in this reasearch is 32 LPD with total 96 of respondents. The research shows indpendensi and objectivity have a positive influence and no significant effect to the supervisory performance. In partially, accountability and work experience have significant and positive influence to the supervisory performance. However the organizational culture partially has negative influence and no significant effect to the supervisory performance LPD.

Key Words : supervisor, performance, organizationalculture, independence, objectivity, accountability, and work experience
\end{abstract}


Kadek Pipit Winarsih dan Ketut Alit Suardana. Pengaruh...

\section{PENDAHULUAN}

Lembaga Keuangan Mikro (micro finance) adalah lembaga yang menyediakan jasa keuangan untuk masyarakat yang mempunyai penghasilan rendah, usaha kecil yang tidak layani oleh lembaga keuangan formal. LKM di Indonesia semakin berkembang hal ini mengidentifikasikan bahwa masyarakat sangat membutuhkan LKM (Wisadha dan Putra, 2013). Lembaga Perkreditan Desa (LPD) merupakan salah satu lembaga keungan yang berdiri untuk yang pertama kalinya pada tahun 1985 di provinsi Bali sebagai badan usaha milik desa yang mempermudah masyarakat untuk memperoleh modal usaha dan kegiatan lainnya. Berdasarkan Peraturan Daerah Provinsi Bali No. 3 Tahun 2017 mengenai LPD pada Pasal 1 menyatakan bahwa LPD adalah Lembaga Keuangan Milik Desa yang bertempat di wilayah Desa Pakraman. Tujuan dibentuknya lembaga ini yaitu untuk mendorong pembangunan ekonomi masyarakat desa melalui tabungan terarah serta penyaluran modal yang efektif.

Peran LPD sangat penting dalam meningkatkan perekonomian masyarakat. Manfaat nyata dari keberadaan LPD dapat dilihat dari kontribusinya yaitu sebesar $20 \%$ dari laba yang diperoleh diserahkan ke desa adat untuk dana pembangunan desa, serta 5\% untuk dana sosial, sehingga beban masyarakat dapat diringankan dalam hal pembangunan desa maupun iuran dana social (Sundarianingsih, 2014). Melihat pentingnya peran LPD bagi masyarakat, maka produktivitas pengurus atau pengelola LPD harus ditingkatkan agar mampu bersaing dengan lembaga keungan lainnya (Ekayani dkk., 2016). 
Pencapaian visi dan misi suatu lembaga organisasi membutuhkan pengelolaan manajerial yang baik, untuk mencapai tujuan tersebut kinerja menjadi hal yang utama untuk dapat meraih itu. Kinerja merupakan proses penilaian atau evaluasi terhadap prestasi kerja dalam suatu organisasi (Putri, 2014). Banyak faktor yang mempengaruhi kinerja pengawas, beberapa faktor diantaranya adalah budaya organisasi, independensi, objektivitas, akuntabilitas, dan pengalaman kerja.

Dipilihnya LPD sebagai objek penelitian, karena perkembangan jumlah LPD di Bali setiap tahunnya selalu meningkat, tidak hanya itu laba yang diperoleh pun semakin tinggi. Jumlah LPD di Bali pada tahun 1984 sampai tahun 2016 adalah sebanyak 1.433 LPD dan mampu menyerap tenaga kerja sebanyak 7.811 orang. Efektivitas pengaturan dan pengawasan LPD dinilai masih meragukan, hal ini dibuktikan dengan banyaknya LPD yang bermasalah, seharunya transparansi dan kejujuran pengawas internal harus diperkuat dengan pelatihan-pelatihan SDM. Jumlah LPD di Kecamatan Tampaksiring cukup dominan dari jumlah lembaga-lembaga keuangan lainnya, dari 7 kecamatan yang ada di Kabupaten Gianyar, pendapatan operasional LPD di Kecamatan Tampangsiring berada di posisi dua terbawah, padahal keberadaa LPD didukung oleh potensi yang dimiliki oleh masayarakat dalam bidang kerajinan seni dan perdagangan. 
Tebel 1

Pendapatan Operasional dan Aset LPD di Kabupaten Gianyar (Dalam Ribuan)

\begin{tabular}{clcccc}
\hline \multirow{2}{*}{ No. } & \multirow{2}{*}{ Kecamatan } & \multicolumn{3}{c}{ Total Pend. Operasioal } & Jumlah Aset \\
& & Th. 2014 & Th. 2015 & Th. 2016 & Th. 2016 \\
\hline 1 & Ubud & 103.926 .639 & 122.260 .571 & 137.925 .296 & 1.108 .053 .386 \\
2 & Sukawati & 59.181 .025 & 69.286 .049 & 76.330 .647 & 596.176 .250 \\
3 & Tegalalang & 53.732 .665 & 61.056 .287 & 67.656 .371 & 491.434 .073 \\
4 & Gianyar & 37.242 .601 & 44.389 .200 & 52.084 .712 & 360.844 .001 \\
5 & Blabatuh & 36.365 .275 & 42.503 .447 & 51.865 .869 & 379.401 .084 \\
6 & Tampaksiring & 22.406 .140 & 24.938 .194 & 28.089 .646 & 203.160 .553 \\
7 & Payangan & 21.686 .147 & 25.019 .428 & 24.535 .251 & 147.051 .272 \\
\hline
\end{tabular}

Sumber: LPD Kabupaten Gianyar, 2017

Budaya organisasi merupakan bagian penting dari sebuah organisasi (Syahrum dkk., 2016). Budaya organisasi bisa menjadi karakteristik suatu organisasi sehingga tiap-tiap oganisasi berbeda antara satu dengan yang lainnya (Nazir dan Shazia, 2015). Budaya adalah norma dan nilai yang membimbing perilaku anggota organisasi. Setiap anggota akan berperilaku sesuai dengan budaya lingkungan yang berlaku agar bisa diterima (Wawo dkk., 2015). Budaya organisasi merupakan instrument yang unggul, bila mampu mengatasi tantangan lingkungan dengan tepat dan cepat dan menjadi pendukung dalam strategi organisasi (Soedjono, 2005).

Hasil penelitian yang telah dilakukan oleh Maradesa dan Budiarso (2017) menunjukkan bahwa budaya organisasi berpengaruh terhadap kinerja inspektorat. Hasil tersebut dapat dipahami bahwa untuk meningkatkan kinerja audit, seorang auditor sangat bergantung pada budaya organisasi. Berdasarkan uraian tersebut diatas, maka dapat dirumuskan hipotesis sebagai berikut: 
$\mathrm{H}_{1}$ : Budaya Organisasi berpengaruh pada kinerja pengawas LPD di Kecamatan Tampaksiring Kabupaten Gianyar.

Independensi adalah sikap yang tidak dipengaruh dan tidak dikendalikan oleh pihak lain (Tepalagul dan Lin, 2015). Independensi juga berarti adanya kejujuran pada diri pengawas dalam mempertimbngkan fakta dan adanya pertimbangan yang objektif. Dari uraian tersebut dapat disimpulkan bahwa independensi seorang pengawas sangat penting dalam menyatakan pendapat dan kualitas atas hasil laporan.

Jika seorang pengawas mampu besikap independen, maka ia akan dapat memberi penilaian sesuai dengan kenyataan pada laporan yang diperiksa tanpa harus memiliki beban pada pihak-pihak manapun. Penilaian yang diberikan adalah cerminan keadaan yang senyatanya dari perusahaan yang diperiksa, dengan begitu maka jaminan lapoaran bisa dipecaya oleh semua pihak yang memiliki kepentingan. Pengawas yang menerapkan independensi yang tinggi akan menghasilkan laporan yang semakin baik.

Hasil penelitian yang dilakukan oleh Kardani (2012) dan Pratiwi (2012) menunjukkan bahwa independensi berpengaruh positif dan signifikan terhadap efektivitas struktur pengendalian intern. Hasil penenilian ini juga didukung oleh penelitian yang dilakukan oleh Prawitasari (2015) yang menunjukkan bahwa independensi berpengaruh positif dan signifikan terhadap kinerja pengawas. Hal ini menunjukkan bahwa meningkatknya independensi pengawas akan berpengaruh terhadap peningkatan kinerja pengawas. Berdasarkan uraian tersebut diatas, maka dapat dirumuskan hipotesis sebagai berikut:

$\mathrm{H}_{2}$ : Independensi berpengaruh pada kinerja pengawas LPD di Kecamatan Tampaksiring Kabupaten Gianyar. 
Kadek Pipit Winarsih dan Ketut Alit Suardana. Pengaruh...

Objektivitas didefinisikan sebagai keadaan dimana pikiran tidak dipengaruhi oleh kepentingan pribadi yang mempengaruhi penilaian-penilaian dan keputusan (Mutchler, 2003). Objektivitas adalah sikap dimana kepentingan pribadi tidak mempengaruhi pelaksanaan tugas pengawasan. Pengawas yang mampu memiliki objektivitas adalah pengawas yang mampu memberi penilaian yang konsisten di semua keadaan tanpa harus terpengaruh oleh kepentingan yang dimiliki oleh orang lain maupun pribadi dalam penentuan keputusan, jika tingkat objektivitas yang dimiliki oleh seorang pengawas tinggi maka kualitas pemeriksaaan yang dilakukan akan semakin baik. Hasil penelitian yang dilakukan oleh Yusuf (2014) menunjukan bahwa objektivitas berpengaruh signifikan terhadap kualitas hasil kerja auditor pada BPKP Perwakilan Riau. Berdasarkan uraian tersebut diatas, maka dapat dirumuskan hipotesis sebagai berikut:

$\mathrm{H}_{3}$ : Objektivitas berpengaruh pada kinerja pengawas LPD di Kecamatan Tampaksiring Kabupaten Gianyar.

Akutabilitas adalah rasa kebertanggungjawaban yang dimiliki oleh pengawas dalam menyelesaikan pekerjaannya. Akuntabilitas adalah rasa kebertanggungjawaban, yang membuat seseorang berusaha untuk bertanggungjawab atas tindakan dan juga keputusan yang diambilnya dimana seseorang tersebut melakukan aktivitas atau pekerjaan yang dapat mempengaruhi keadaan sekitarnya (Augustine dan Matthew, 2014). Menurut Usman (2016) akuntabilitas adalah bentuk dorongan psikologis yang membuat orang bertanggungjawab untuk setiap tindakan dan keputusan yang diambil. Dengan memiliki rasa tanggung jawab, maka pengawas akan termotivasi untuk bekerja 
dengan baik, memiliki suatu komitmen tanda paksaan dari pihak lain dan yakin jika pekerjaan dilakukan dengan sangat baik, maka kontribusi yang diberikan kepada masyarakat akan semakin baik. Hasil Penelitian yang dilakukan oleh Hendra (2011) menunjukkan bahwa akuntabilitas berpengaruh pada kualitas audit. Hasil penelitian yang dilakukan oleh Pratiwi (2012) menunjukkan bahwa akuntabilitas berpengaruh positif dan signifikan pada efektivitas penerapan pengendalian intern. Berdasarkan uraian tersebut diatas, maka dapat dirumuskan hipotesis sebagai berikut:

$\mathrm{H}_{4}$ : Akuntabilitas berpengaruh pada kinerja pengawas LPD di Kecamatan Tampaksiring Kabupaten Gianyar.

Terlepas dari pengetahuan akademis, biasanya pengalaman itu memainkan peran yang penting dalam kinerja individu (Kotur dan Anbazhagan, 2014). Pengalaman kerja bisa menambah kemampuan kerja, karena dengan seringnya melakukan pekerjaan yang sama maka pekerjaannya akan lebih cepat selesai. Semakin banyak jenis pekerjaan di mana orang tersebut bekerja semakin kaya pengalaman dan memungkinkan peningkatan kinerja (Usman, 2016). Pengalaman kerja adalah hal penting di segala organisasi, baik disektor informal ataupun diinternal perusahaan. Tingginya pengalaman kerja yang dimiliki oleh pengawas akan meningkatkan kinerja perusahaan maupun dirinya sendiri, dengan demikian pekerjaan akan mampu berjalan dengan baik (Tubbs, 1998). Hasil Penelitian Wijayanti (2012) menunjukkan bahwa pengalaman kerja berpengaruh efektivitas penerapan pengendalian intern. Hasil penelitian tersebut juga didukung oleh penelitian yang dilakukan Murtini (2017) yang meunjukkan bahwa pengalaman 
Kadek Pipit Winarsih dan Ketut Alit Suardana. Pengaruh...

kerja berpengaruh positif dan signifikan terhadap kinerja pengawas. Berdasarkan uraian tersebut diatas, maka dapat dirumuskan hipotesis sebagai berikut:

$\mathrm{H}_{5}$ : Pengalaman Kerja berpengaruh pada kinerja pengawas LPD di Kecamatan Tampaksiring Kabupaten Gianyar.

\section{METODE PENELITIAN}

Desain penelitian yang digunakan dalam penelitian ini adalah pendekatan asosiatif tipe kausalitas. Lokasi atau ruang lingkup penelitian ini dilakukan pada Lembaga Perkreditan Desa (LPD) yang ada di Kecamatan Tampaksiring Kabupaten Gianyar. Kinerja pengawas (Y) adalah variabel terikat $(\mathrm{Y})$ dalam penelitian ini sedangkan budaya organisasi $\left(\mathrm{X}_{1}\right)$, independensi $\left(\mathrm{X}_{2}\right)$, objektivitas $\left(\mathrm{X}_{3}\right)$, akuntabilitas $\left(\mathrm{X}_{4}\right)$, dan pengalaman kerja $\left(\mathrm{X}_{5}\right)$ adalah variabel bebas $(\mathrm{X})$.

Populasi dalam penelitian ini adalah keseluruhan LPD di Kecamatan Tampaksiring Kabupaten Gianyar yang masih aktif beroperasi. Responden yang dipilih merupakan orang yang mengetahui wewenang, fungsi, dan tugas pengawas dalam pemberian nilai kinerja pengawas. Orang-orang yang dimaksud adalah pengawas LPD. Penentuan sampel yang digunakan adalah purposive sampling. Kriteria sampel yang digunakan adalah pengawas LPD di Kecamatan Tampaksiring yang telah menduduki jabatan selama minimal dua tahun, hal ini dikarenakan masa jabatan minimal dua tahun dianggap telah berpengalaman. Jumlah sampel yang didapat adalah 96 orang dari 32 LPD, karena dari seluruh populasi memenuhi kriteria sempel.

Metode pengumpulan data yang digunakan dalam penelitian ini adalah motode dokumentasi dan kuesioner. Dimana data yang didapat adalah data 
perkembangan LPD dan keragaman LPD. Kuisioner yang digunakan adalah kuisioner terstruktur, dimana responden memberikan tanda checklist pada jawaban pernyataan menurut skala yang telah ditentukan. Pengukuran jawaban responden menggunakan skala likert modifikasi, dengan pemberian nilai 1 sampai 4. Pernyataan mengenai variabel budaya organisasi $\left(X_{1}\right)$ terdiri dari 5 item, indikator-indikator dari variabel ini terdiri dari unsur kejelasan, intensitas pelaksanaan nilai budaya, ritual, penyesuaian diri, dan loyalitas. Variabel independensi $\left(\mathrm{X}_{2}\right)$ terdiri dari 6 item, Indikator-indikator dari variabel ini terdiri dari status organisasi dan kejujuran dalam melaksanakan tugas. variabel objektivitas $\left(\mathrm{X}_{3}\right)$ terdiri dari 7 item, indikator-indikator dari variabel ini terdiri dari bebas dari benturan kepentingan dan pengungkapan kondisi sesuai fakta. Variabel akuntabilitas terdiri dari 7 item, indikator-indikator variabel ini terdiri dari motivasi, pengabdian kepada profesi, dan kewajiban sosial. Variabel pengalaman kerja terdiri dari 6 item, indikator-indikator dari variabel ini terdiri dari kepekaan pendektesian kekeliruan, penyelesaiaan tugas secara tepat waktu, dan kemampuan penggolongan kekeliruan. Variabel kinerja terdiri dari 13 item, indikator-indikator dari variabel ini terdiri dari produksi (Production), efektivitas (effective), efisien (efficiency), keadaptasian (Adaptiveness), kepuasan (Satisfaction), dan pengembangan (Development). Teknik analisi yang digunakan dalam penelitian ini adalah analisis regresi linier berganda. Analisis regresi linier berganda merupakan analisis untuk memperoleh gambaran tentang variabel terikat yang dipengaruhi oleh variabel bebas (Sugiyono, 2017:270). Model regresi linier berganda dapat dinyatakan dengan persamaan sebagai berikut: 
$Y=\alpha+\beta_{1} X_{1}+\beta_{2} X_{2}+\beta_{3} X_{3}+\beta_{4} X_{4}+\beta_{5} X_{5}+\varepsilon$

Keterangan :

$\mathrm{Y} \quad$ : Kinerja Pengawas

$\alpha \quad$ : Konstanta

$\beta_{1}-\beta_{5}$ : Koefisien regresi variabel $X_{1}, X_{2}, X_{3}, X_{4}$, dan $X_{5}$

$\mathrm{X}_{1} \quad$ : Budaya Organisasi

$\mathrm{X}_{2} \quad$ : Independensi

$\mathrm{X}_{3}$ : Objektivitas

$\mathrm{X}_{4}$ : Akuntabilitas

$\mathrm{X}_{5} \quad$ : Pengalaman Kerja

$\varepsilon \quad:$ Standar Error

\section{HASIL DAN PEMBAHASAN}

Uji Validitas digunakan untuk mengukur sah atau valid tidaknya suatu kuisioner.

Suatu instrumen dikatakan memenuhi validitas apabila korelasi antara skor butir dengan skor total tersebut positif dan lebih besar dari 0,30 dengan tingkat kesalahan alpha 0,5 (Sugiyono, 2017:126). Semua hasil uji validitas (nilai pearson correlation) dari masing-masing pertanyaan mengenai budaya organisasi $\left(\mathrm{X}_{1}\right)$, independensi $\left(\mathrm{X}_{2}\right)$, objektivitas $\left(\mathrm{X}_{3}\right)$, akuntabilitas $\left(\mathrm{X}_{4}\right)$, dan pengalaman kerja $\left(\mathrm{X}_{5}\right)$ lebih besar dari 0,30 , hal ini menunjukkan berarti semua pernyataan yang ada didalam penelitian adalah valid.

Tabel 2

Hasil Uji Reliabilitas

\begin{tabular}{ccc}
\hline Variabel & $\begin{array}{c}\text { Cronbach's } \\
\text { Alpha }\end{array}$ & Keterangan \\
\hline Budaya Organisasi $\left(\mathrm{X}_{1}\right)$ & 0,702 & Reliabel \\
Independensi $\left(\mathrm{X}_{2}\right)$ & 0,706 & Reliabel \\
Objektivitas $\left(\mathrm{X}_{3}\right)$ & 0,835 & Reliabel \\
Akuntabilitas $\left(\mathrm{X}_{4}\right)$ & 0,795 & Reliabel \\
Pengalaman Kerja $\left(\mathrm{X}_{5}\right)$ & 0,760 & Reliabel \\
Kinerja (Y) & 0,911 & Reliabel \\
\hline Sumber: Data diolah, 2017 & &
\end{tabular}


Berdasarkan Tabel 2 dapat disimpulkan bahwa hasil uji reliabilitas menunjukkan bahwa nilai cronbach's alpha >0,60. Hal ini berarti bahwa instrumen yang digunakan adalah reliable.

\section{Tabel 3}

Hasil Uji Normalitas

\begin{tabular}{|c|c|c|}
\hline Variabel & $\begin{array}{c}\text { Komolgorov-Smirnov } \\
Z \\
\end{array}$ & Asymp. Sig. (2-tailed) \\
\hline $\mathrm{Y}$ & 0,233 & 0,098 \\
\hline $\mathrm{X}_{1}$ & 0,176 & 0,200 \\
\hline $\mathrm{X}_{2}$ & 0,173 & 0,200 \\
\hline $\mathrm{X}_{3}$ & 0,248 & 0,082 \\
\hline $\mathrm{X}_{4}$ & 0,243 & 0,096 \\
\hline $\mathrm{X}_{5}$ & 0,182 & 0,196 \\
\hline
\end{tabular}

Berdasarkan Tabel 3 maka dapat dijelaskan bahwa koefisien Asymp. Sig. (2-tailed) variabel kinerja (Y) sebesar 0,098, variabel budaya organisasi $\left(\mathrm{X}_{2}\right)$ sebesar 0,200 , variabel indpendensi $\left(\mathrm{X}_{3}\right)$ sebesar 0,200, variabel objektivitas $\left(\mathrm{X}_{4}\right)$ sebesar 0,082, variabel akuntabilitas $\left(\mathrm{X}_{4}\right)$ sebesar 0,096, dan variabel kinerja pengawas $\left(\mathrm{X}_{5}\right)$ sebesar 0,196 yang berarti lebih besar dari taraf signifikan 0,05. Hal ini menunjukkan bahwa semua variabel dalam penelitian berdistribusi normal.

Tabel 4

Hasil Uji Multikolinearitas

\begin{tabular}{lcc}
\multicolumn{1}{c}{ Variabel } & \multicolumn{2}{c}{ Collinearity Statistic } \\
& Tolerance & VIF \\
\hline Budaya Organisasi $\left(\mathrm{X}_{1}\right)$ & 0,762 & 1.312 \\
Independensi $\left(\mathrm{X}_{2}\right)$ & 0,659 & 1.519 \\
Objektivitas $\left(\mathrm{X}_{3}\right)$ & 0,843 & 1.186 \\
Akuntabilitas $\left(\mathrm{X}_{4}\right)$ & 0,598 & 1.671 \\
Pengalaman Kerja $\left(\mathrm{X}_{5}\right)$ & 0,750 & 1.334 \\
\hline Sumber: Data diolah, 2017 & &
\end{tabular}


Kadek Pipit Winarsih dan Ketut Alit Suardana. Pengaruh...

Berdasarkan Tabel 4 maka dapat dijelaskan bahwa nilai tolerance masingmasing variabel lebih besar 0,1 dan nilai variance inflation factor (VIF) lebih kecil dari 10. Hal ini berarti bahwa dalam model regresi tidak terjadi multikolinearitas dan dapat digunakan dalam penelitian ini

\section{Tabel 5}

Hasil Uji Heteroskedastisitas

\begin{tabular}{lcc}
\hline \multicolumn{1}{c}{ Variabel } & Sig. & Keterangan \\
\hline Budaya Organisasi $\left(\mathrm{X}_{1}\right)$ & 0,100 & Bebas Heteroskedastisitas \\
Independensi $\left(\mathrm{X}_{2}\right)$ & 0,567 & Bebas Heteroskedastisitas \\
Objektivitas $\left(\mathrm{X}_{3}\right)$ & 0,567 & Bebas Heteroskedastisitas \\
Akuntabilitas $\left(\mathrm{X}_{4}\right)$ & 0,269 & Bebas Heteroskedastisitas \\
Pengalaman Kerja $\left(\mathrm{X}_{5)}\right.$ & 0,805 & Bebas Heteroskedastisitas \\
\hline
\end{tabular}

Sumber: Data diolah, 2017

Berdasarkan Tabe 5 di atas dapat dilihat bahwa nilai signifikan dari masing-masing variabel bebas berada di atas 0,05 . Hal ini berarti model regresi dalam penelitian tidak mengandung gejala heteroskedastisitas.

Tabel 6

Hasil Regresi Linier Berganda

\begin{tabular}{|c|c|c|c|c|c|}
\hline \multirow{2}{*}{$\begin{array}{c}\text { Hasil Analisis Regresi Linier } \\
\text { BergandaModel }\end{array}$} & \multicolumn{2}{|c|}{$\begin{array}{l}\text { Unstandardized } \\
\text { Coefficients }\end{array}$} & \multirow{2}{*}{$\begin{array}{c}\text { Standardized } \\
\text { Coefficients } \\
\text { Beta }\end{array}$} & \multirow[t]{2}{*}{$\mathbf{T}$} & \multirow[t]{2}{*}{ Sig. } \\
\hline & B & Std. Error & & & \\
\hline (Constant) & 8.871 & 4.830 & & 1.837 & .071 \\
\hline Budaya Organisasi & -.133 & .269 & -.050 & -.495 & .623 \\
\hline Independensi & .274 & .190 & .155 & 1.439 & .155 \\
\hline Objektivitas & .099 & .096 & .098 & 1.031 & .306 \\
\hline Akuntabilitas & .668 & .209 & .362 & 3.203 & .002 \\
\hline Pengalaman Kerja & .682 & .186 & .371 & 3.671 & .001 \\
\hline R Square & & & & & 0,525 \\
\hline Adjust R Square & & & & & 0,487 \\
\hline F Hitung & & & & & 13,698 \\
\hline Sig.F & & & & & 0,000 \\
\hline
\end{tabular}

Dari tabel diatas dapat diperoleh persamaan regresi linier sebagai berikut:

$Y=8,871-0,133 X_{1}+0,274 X_{2}+0,099 X_{3}+0,668 X_{4}+0,682 X_{5}$ 
Nilai konstanta sebesar 8,871 yang berarti bahwa, jika budaya organisasi $\left(\mathrm{X}_{1}\right)$, Independensi $\left(\mathrm{X}_{2}\right)$, Objektivitas $\left(\mathrm{X}_{3}\right)$, akuntabilitas $\left(\mathrm{X}_{4}\right)$ dan pengalaman kerja $\left(\mathrm{X}_{5}\right)$ sama dengan nol maka kinerja pengawas $(\mathrm{Y})$ adalah 08,871 satuan. Nilai koefisien $\beta_{1}=-0,133$ menunjukkan bahwa jika budaya organisasi $\left(\mathrm{X}_{1}\right)$ bertambah 1 satuan dengan asumsi variabel bebas lainnya konstan maka nilai kinerja pengawas (Y) akan turun sebesar 0,133 satuan. Nilai koefisien $\beta_{2}=0,274$ menunjukkan bahwa jika independensi $\left(\mathrm{X}_{2}\right)$ bertambah 1 satuan dengan asumsi bahwa variabel bebas lainnya konstan maka nilai kinerja pengawas (Y) akan bertambah sebesar 0,274 satuan. Nilai koefisien $\beta_{3}=0,099$ menunjjukan bahwa jika objektivitas $\left(\mathrm{X}_{3}\right)$ bertambah 1 satuan dengan asumsi bahwa variabel bebas lainnya konstan maka nila kinerja pengawas (Y) akan bertambah sebesar 0,099 satuan. Nilai koefisien $\beta_{4}=0,668$ menunjukkan bahwa jika akuntabilitas $\left(\mathrm{X}_{4}\right)$ bertambah 1 satuan maka dengan asumsi bahwa variabel bebas lainnya konstan maka nilai kinerja pengawas (Y) akan bertambah sebesar 0,668 satuan. Nilai Koefisien $\beta_{5}=0,682$ menunjukkan bahwa jika pengalaman kerja $\left(\mathrm{X}_{5}\right)$ bertambah 1 satuan maka dengan asumsi bahwa variabel bebas lainnya konstan maka nilai kinerja pengawas (Y) akan bertambah 0,682 satuan.

Nilai Adjusted R square pada Tabel 6 adalah sebesar 0,487 atau 48,7\%. Hal ini menjelaskan bahwa variasi kinerja pengawas dapat dijelaskan oleh variasi budaya organisasi, independensi, objektivitas, akuntabilitas dan pengalaman kerja sebesar $48,7 \%$ sedangkan sisanya sebesar $51,3 \%$ dijelaskan oleh faktor-faktor lain yang tidak dimasukkan kedalam model regresi. 
Kadek Pipit Winarsih dan Ketut Alit Suardana. Pengaruh...

Nilai F pada Tabel 6 adalah sebesar 13,698 dengan tingkat signifikansi sebesar $0,000<0,05$. Hal ini berarti bahwa budaya organisasi, independensi, objektivitas, akuntabilitas, dan pengalaman kerja mampu memprediksi atau menjelaskan kinerja pengawas dengan demikian dapat disimpulkan bahwa model regresi linier berganda dalam penelitian ini dikatakan layak digunakan sebagai alat analisis untuk menguji pengaruh variabel independen pada variabel dependen.

Berdasarkan Tabel 6 menunjukkan bahwa nilai t pada variabel budaya organisasi sebesar -0.495 dengan tingkat signifikansi sebesar 0,623 $>0,05$. Diperoleh hasil bahwa variabel budaya organisasi berpengaruh negatif dan tidak signfikan terhadap kinerja pengawas LPD. Hasil penelitian ini tidak sejalan dengan yang dilakukan oleh Maradesa dan Budiarso (2017) yang menunjukkan bahwa budaya organisasi berpengaruh positif terhadap kinerja inspektorat. Hal tersebut menujukkan bahwa semakin tinggi budaya organisasi maka kinerja pengawas semakin menurun.

Berdasarkan Tabel 6 menunjukkan bahwa nilai $\mathrm{t}$ pada variabel independensi sebesar 1.439 dengan tingkat signifikansi sebesar 0,155 >0,05. Hal ini berarti bahwa variabel independensi berpengaruh positif namun tidak signifikan terhadap kinerja pengawas. Sehingga dapat disimpulkan bahwa independensi seorang pengawas dalam penelitian ini tidak mempengaruhi kinerja pengawas secara signifikan. Hasil penelitian ini menunjukkan bahwa semakin baik independensi pengawas pada LPD di Kecamatan Tampaksiring Kabupaten Gianyar maka akan membuat kinerja pengawas semakin baik. Namun independensi tidak berpengaruh secara langsung terhadap kinerja pengawas Hasil 
penelitian ini juga didukung oleh hasil penelitian dari Salju, dkk (2014) menyatakan bahwa independensi terbukti berpengaruh positif terhadap kinerja pengawas. Mencermati bahwa independensi berpengaruh pada kinerja pengawas LPD, sebaiknya pemilihan kriteria pengawas independen yaitu memiliki sikap tidak memihak, serta dalam pengawasan dan penilian kebijakan maupun prosedur yang telah ditetapkan oleh LPD mampu mengungkapkan fakta. Kinerja pengawas akan semakin optimal ketika pengawas memiliki sikap independen.

Berdasarkan Tabel 6 menunjukkan bahwa nilai t pada variabel objektivitas sebesar 1.031 dengan tingkat signifikansi sebesar 0,306 >0,05. Menunjukkan bahwa variabel independensi berpengaruh positif namun tidak signifikan terhadap kinerja pengawas. Semakin baik objektivitas seorang pengawas akan semakin baik kualitas hasil kerja pengawas. Namun objektivitas tidak mempengaruhi kinerja pengawas secara langsung. Hasil penenlitian ini didukung oleh hasil penenlitian dari Yusuf (2014) yang menyatakan bahwa objektivitas berpengaruh positif terhadap kualitas hasil kerja auditor pada BPKP Perwakilan Riau. Objektivitas merupakan aspek yang penting bagi seorang pengawas, karena pengawas membutuhkan kepercayaan dari masyarakat. Objektivtas adalah landasan kepercayaan masyarakat pada pengawas untuk penilaian hasil kerja agar dipercaya keobjektivannya.

Berdasarkan Tabel 6 menunjukkan bahwa nilai t pada variabel objektivitas sebesar 3.203 dengan tingkat signifikansi sebesar 0,002 <0,05. Hal ini berarti bahwa variabel akuntabilitas berpengaruh positif dan signifikan terhadap kinerja pengawas. Semakin tinggi akuntabilitas seorang pengawas maka kinerja 
Kadek Pipit Winarsih dan Ketut Alit Suardana. Pengaruh...

pengawas dalam menyelesaikan pekerjaan akan semakin baik. Hasil penelitian ini juga didukung oleh hasil penelitian dari Pratiwi (2012) menunjukkan bahwa akuntabilitas berpengaruh positif dan signifikan pada efektivitas penerapan pengendalian intern. Dengan memiliki rasa tanggung jawab, maka pengawas akan termotivasi untuk bekerja dengan baik, memiliki suatu komitmen tanpa paksaan dari pihak lain dan mempunyai suatau kepercayaan jika pekerjaan dilakukan dengan sangat baik, maka akan dapat memberi kontribusi yang tinggi untuk masyarakat. Hal ini tentunya berdampak positif pada kinerja pengawas. Semakin meningkat akuntabilitas pengawas maka kinerja pengawas LPD akan semakin meningkat. Berdasarkan Tabel 6 menunjukkan bahwa nilai $\mathrm{t}$ pada variabel objektivitas sebesar 3.671 dengan tingkat signifikansi sebesar $0,001<0,05$. Hal ini berarti bahwa variabel pengalaman kerja berpengaruh positif dan signifikan terhadap kinerja pengawas.

Semakin banyak pengalaman yang dimiliki pengawas akan meningkatkan kinerja pengawas menjadi semakin baik dan begitu juga sebaliknya. Dengan demikian agar kinerja pengawas LPD meningkat bisa dilakukan dengan memperluas pengalaman kerja yang dimiliki oleh pengawas. Hasil penelitian ini sejalan dengan penelitian yang dilakukan oleh Murtini (2017) yang menyatakan bahwa pengalaman kerja terbukti berpengaruh positif dan signifikan terhadap kinerja badan pengawas. Kemampuan kerja yang dimiliki oleh pengawas bisa diperdalam dengan pengalaman kerja. Keterampilan dan kecepatan seseorang dalam menyelesaikan pekerjaan didapat dengan melaksanakan pekerjaan yang 
sama. Jika semakin banyak dan semakin luas pengalaman yang dimiliki oleh seorang pengawas, maka akan dapat meningkatkan kinerja pengawas.

\section{SIMPULAN DAN SARAN}

Berdasarkan pembahasan hasil penelitian maka dapat disimpulan bahwa Independensi dan objektivitas secara parsial berpengaruh positif namun tidak signifikan terhadap kinerja pengawas LPD di Kecamatan Tampaksiring Kabupaten Gianyar. Akuntabilitas dan pengalaman kerja secara parsial berpengaruh positif dan signifikan terhadap kinerja pengawas LPD di Kecamatan Tampaksiring Kabupaten Gianyar, sedangkan budaya organisasi berpengaruh negatif terhadap kinerja pengawas LPD di Kecamatan Tampaksiring Kabupaten Gianyar. Saran yang dapat diberikan dalam penelitian ini adalah faktor-faktor independensi dan objektivitas harus lebih diperhatikan oleh pengurus LPD, karena sikap indepedensi dan objektivitas yang dimiliki pengawas akan menciptakan suatu pengawasan yang jujur dan tidak memihak serta mampu mengungkapkan fakta-fakta yang sesuai dengan pengawasan yang dilakukan.

\section{REFERENSI}

Augustine dan Matthew.2014. The Effect Effectiveness of Accountibility and Transparency In GovermentSectors. Journal of Business and Management. 16 (4), pp.45-54

Ekayani, Ni Putu., Edy Sujana., Made Arie Wahyuni. 2016. Pengaruh Budaya Organisasi, Gaya Kepemimpinan, dan Pengalaman Kerja Terhadap Efektivitas Sistem Pengendalian Intern Pada Lembaga Perkreditan Desa (LPD) Se-Kecamatan Payangan Kabupaten Gianyar. e-JurnalS1 Ak Universitas Pendidikan Ganesha, 7 (1), hal.4-12

Hendra Surya, I Wayan. 2011. Pengaruh Independensi, Pengalaman Kerja, Due Profesional Care, dan Akuntabilitas Auditor pada Kualitas Audit Auditor Kantor Akuntan Publikdi Bali. Skripsi Sarjana Jurusan Akuntansi pada Fakultas Ekonomi dan Bisnis Universitas Udayana, Bali. 
Kardani, Ni Made Dwi. 2012. Pengaruh Independensi, Keahliam Profesional, dan Pengalaman Kerja Badan Pengawas Terhadap Struktur Pengendalian Intern Lembaga Perkreditan Desa (LPD) di Kecamatan Tabanan. Skripsi Sarjana Jurusan Akuntansi pada Fakultas Ekonomi dan Bisnis Universitas Udayana, Bali.

Kotur, Bhargava R., and S. Anbhazhagan. 2014. Education and Work Experience Influence on The Performance. Journal of Business and Management. 16 (5), pp.104-110

Maradesa, Christony dan Novi S. Budiarso. 2017. Analisis Pengaruh Budaya Organisasi Dan Gaya Kepemimpinan Terhadap Kinerja Aparat Pengawas Intern Pemerintah Daerah Provinsi Sulawesi Utara. Jurnal Accountability, 06 (1), hal.28-34.

Murtini, Ni Nengah. 2017. Pengaruh Independensi, Keahlian Profesional, Pengalaman Kerja, dan Tingkat Pendidikan Pada Kinerja Pengawas Koperasi di Kecamatan Rendang Kabupaten Karangasem. E-Jurnal Akuntansi Universitas Udayana, 20 (2), hal.1390-1418.

Mutchler, Jane F. 2003. Independence ad Objectivity: A Framework for Research Opportunity in Internal Auditing. The Institute of Internal Auditors Research Foundation. http://citeseerx.ist.psu.edu/viewdoc/download. Diakses 5 Juli 2017.

Nazir, Nadia and Shazia Zamir. 2015. Impact of Organizational Culture on Employee's Performance. Industrial Engineering Letters, 5 (9), hal.31-37

Peraturan Daerah Provinsi Bali No. 3 Tahun 2017 tentang Lembaga Perkreditan Desa. http://jdih.baliprov.go.id/upload/produk/2017/perda-3-2017. Diakses 20 Mei 2017.

Pratiwi, Ida Yuni. 2012. Pengaruh Keahlian profesional, Independensi, Etika Profesi, Akuntabilitas, dan Pengalaman Kerja Badan Pengawas Pada Efektivitas Penerapan Pengendalian Intern Lembaga Perkreditan Desa di Kecamatan Sukawati Kabupaten Gianyar. Skripsi Sarjana Jurusan Akuntansi pada Fakultas Ekonomi Universitas Udayana, Bali.

Prawitasari, Putu Putri. 2015. Pengaruh Independensi, Keahlian Profesional, Dan Pengalaman Kerja Pada Kinerja Pengawas Koperasi Serba Usaha. EJurnal Akuntansi Universitas Udayana, 11 (1), hal.15-28.

Putri, Ana Suseno. 2014. Pengaruh Komitmen Organisasi, Gaya Kepemimpinan, Budaya Organisasi Dan Kepuasan Kerja Terhadap Kinerja Organisasi 
Publik.http://eprints.ums.ac.id/39223/1/Naskah\%20Publikasi.pdf.Diakses 5 Juni 2017.

Salju., Rismawati., dan Muhammad Dirga Bachtiar. 2014. Pengaruh Kompetensi dan Independensi Terhadap Kinerja Auditor Pemerintah Kabupaten Luwu Timur. Jurnal Equilibrium, 4 (2), hal.100-123.

Soedjono. 2005. Pengaruh Budaya Organisasi Terhadap Kinerja Organisasi dan Kepuasan Kerja Karyawan Pada Terminal Penumpang Umum di Surabaya. Jurnal Ekonomi Manajemen \& Kewirausahaan, 7 (1), hal.2247.

Sugiyono. 2017. Metode Penelitian Kuantitatif Kualitatif R\&B. Bandung: Alfabeta.

Sundarianingsih, Pera. 2014. Evaluasi Keberhasilan LPD Dalam Menggerakkan Sosial Ekonomi Masyarakat Pedesaan (Studi Pada LPD Desa Adat Pekutatan). Jurnal Ekonomi pembangunan, 12 (1), hal.69-85.

Syahrum, Andi., Ida Aju Brahmasari., Riyadi Nugroho. 2016. Effect of Competence, Organization Culture and Climate of Organization to the Organization Cimmitment, Job Statisfaction and the Performance of Employees in the Scope Of Makasar City Government. Internarional Journal of Business and Management Invention, 5 (4), pp.52-64.

Tepalagul, Nopmanee dan Ling Lin. 2015. Auditor Independence and Audit Quality. International Journal Of Accounting Auditing and Finance, 30 (1), hal.101-121.

Tubbs, R. M. 1998. The Effect Of Experience On The Auditor's Organizational and Amount Of Knowledge The Accounting Riview. 57(4), pp.783-801

Usman. 2016. Effect Of Experience And Accountability On The Quality Of Internal Audit. International Journal Of Scientific \& Technology Research, 5 (3), pp.85-90.

Wawo, Andi Basru., Nur Asni., Sitti Nurnaluri. 2015. The influence of organizational culture, ethical awareness and experience to ethical judgments auditor through Professional commitment (Study at Inspectorate Sub-Province of Bombana). The International Journal of Engineering And Science (IJES), 4 (12), pp.15-25.

Wijayanti, I Gusti Ayu Dwi. 2012. Pengaruh Independensi, Pengalaman Kerja, dan Keahlian Profesional Badan Pengawas Pada Efektivitas Penerapan Pengendalian Intern lembaga Perkreditan Desa (LPD) di Kecamatan Ubud 
Kadek Pipit Winarsih dan Ketut Alit Suardana. Pengaruh...

Kabupaten Gianyar. Skripsi Sarjana Jurusan Akuntansi pada Fakultas Ekonomi dan Bisnis Universitas Udayana, Bali.

Wisadha, I Gede Suparta dan I Gede Adi Dharma Putra. 2013. Pengaruh Profesionalisme, Independensi, dan Pengalaman Auditor Pada KualitasAudit Badan Pengawas Lembaga Perkreditan Desa (LPD). Jurnal Ilmiah Akuntansi dan Bisnis, 8 (2), hal.89-98.

Yusuf, Muhammad. 2014. Pengaruh Kompetensi, Objektivitas Dan Integritas Auditor Terhadap Kualitas Hasil Kerja Auditor (Studi Empiris Pada Auditor BPKP Provinsi

Riau). http://ejournal.unp.ac.id/students/index.php/akt/articel/download/1568/11 91. Diakses 5 Juli 2017 